\title{
Visual Function Tests as a Cost Effective Screening Tool for Diabetic Retinopathy
}

\author{
Faryal Ahmed ${ }^{1}$, Faraz Iftikhar Malik ${ }^{2}$, Chaudhary Ehtsham Azmat ${ }^{3}$, Ambreen Gul $^{4}$, Ali Raza ${ }^{5}$ \\ ${ }_{1,2,3}$ Rawalpindi Medical University and Allied Hospitals \\ ${ }^{4,5}$ Department at Ophthalmology Unit, Holy Family Hospital, Rawalpindi
}

\begin{abstract}
Purpose: To find out the importance of visual function tests as cost effective screening tools for diabetic retinopathy.

Study Design: Descriptive, Cross sectional study.

Place and Duration of Study: Ophthalmology Unit of Holy Family Hospital, from September 2018 to November 2018.

Material and Methods: Two hundred and forty-two patients were selected by convenience sampling technique and were divided into three groups. Two groups of diabetics with and without retinopathy and one group of nondiabetics age-matched controls. After relevant history, patients were examined for Visual acuity, Color vision and Contrast sensitivity using Snellen's Chart, 24 Plates Ishihara Chart and Pelli Robson Chart respectively. Staging of retinopathy was done after mydriasis.

Results: Diabetic patients irrespective of type and stage, when compared with non-diabetic patients had a greater percentage of abnormal visual function tests. A $6 / 6$ visual acuity was observed in $38.2 \%$ of non diabetics as compared to only $8.6 \%$ diabetics without retinopathy and $7.5 \%$ of diabetics with retinopathy. Color vision abnormalities were detected in only $8.6 \%$ of non diabetic patients. However, $11.1 \%$ of diabetics without retinopathy and $23.7 \%$ with retinopathy showed abnormalities of color vision. The percentage of abnormal Contrast sensitivity was $76.2 \%$ for diabetics with retinopathy and $60.4 \%$ for diabetics without retinopathy and $27.1 \%$ for non-diabetic patients.

Conclusion: Evaluation of Visual Acuity, Color Vision and Contrast Sensitivity are cheap and easy tests that can be used to screen for diabetic retinopathy thereby allowing early interventions to prevent development of serious ocular diabetic complications.
\end{abstract}

Key Words: Visual Acuity, Color Vision, Contrast Sensitivity, Diabetic Retinopathy.

How to Cite this Article: Ahmed F, Malik Fl, Azmat CE, Gul A, Raza A. Visual Function Tests as a Cost Effective Screening Tool for Diabetic Retinopathy, Pak J Ophthalmol. 2020; 36 (1): 62-66.

DOI: https://doi.org/10.36351/pjo.v36i1.887.

\section{INTRODUCTION}

Diabetes mellitus is the leading cause of legal and irreversible blindness throughout the world ${ }^{1}$. Diabetic

Correspondence to: Faryal Ahmed,

House Officer

Rawalpindi Medical University and Allied Hospitals

Email: faryal.ahmed8@gmail.com eye disease pertains diabetic retinopathy, cataract, glaucoma, macular edema with Diabetic Retinopathy (DR) being the most common ocular complication. Visual function changes appear in diabetics before any appreciable structural abnormalities can be detected by ophthalmoscopy and fluorescein angiography ${ }^{2,3}$. These changes include impaired Visual Acuity (VA), abnormal Contrast Sensitivity (CS) and defects in Color Vision (CV). 
Different tests have been devised to predict the development of $\mathrm{DR}^{4,5}$. Of which, Visual Function Tests are being recognized as sensitive screening tools before the development of clinically detectable DR and it may differentiate between various causes of visual loss.

The number of diabetics in Pakistan ranges from 6.2 million with one in every three diabetics suffering from diabetic eye disease. The purpose of this study is to find the determinative ability of Visual Function Tests as cost effective screening tools in patients with DR.

\section{MATERIAL AND METHODS}

A hospital based, cross sectional study was carried out among three groups of patients; 2 groups of diabetics, of which one had diabetic retinopathy and the other had normal fundi. The third group was non-diabetic group. This study was conducted from September 2018 to November 2018 at Ophthalmology Unit of Holy Family Hospital, Rawalpindi.

The sample size was calculated by using the WHO sample size calculator. While keeping the level of confidence at $95 \%$, absolute precision at $0.5 \%$ and prevalence at $19.5 \%$, the minimum required sample size turned out to be 242 .

All 242 patients, of age group 25 to 65 years were examined for their visual acuity, color vision, contrast sensitivity and stage of diabetic retinopathy. Patients with cataract, glaucoma, macular disorders, anterior segment pathologies and those having $+4 / 5$ spherical DS or above were excluded from the study. Informed consent was taken from all the subjects after explaining to them the purpose of the study. The data was collected with the help of a structured questionnaire. The questionnaire was formulated to collect demographic details of all patients with their diabetic status, visual acuity, contrast sensitivity and color vision. The diabetics were asked about type of diabetes, duration of diabetes, control of diabetes and the kind of treatment they were taking.

The diabetic patients were classified on the basis of presence or absence of diabetic retinopathy. All diabetics were examined for stage of diabetic retinopathy using slit lamp Biomicroscopy, 90D lens and fundus photography following mydriasis. In this study, eyes were classified as no diabetic retinopathy (DR), non-proliferative diabetic retinopathy (NPDR), proliferative diabetic retinopathy (PDR) and macular edema. Visual acuity of all patients was measured using a Snellen Chart at a distance of $6 \mathrm{~m}$. Color vision was tested using Ishihara 24 plates chart. The color vision was regarded as normal when greater than equal to 13 plates were read normally and abnormal when less than 9 plates were read normally. The plates were held at an arm's length $(25$ to $30 \mathrm{~cm}$ ) from patient's eyes.

Contrast Sensitivity (CS) was assessed by using Pelli Robson Contrast Sensitivity Acuity Chart. Testing was carried out at a distance of $1 \mathrm{~m}$ (40 inches) with patients wearing their distance correction $^{6,7}$. Pelli Robson Chart consists of horizontal lines of capital letters (6 per line), in which the contrast of letters decreases with each line. This chart tests patient's ability to detect letters that are gradually less contrasted against a white background. Each group has 3 letters of same contrast level, the score, a single number, is a measure of patient's $\log$ CS. Thus a score of 2 means, that the subject was able to read at least 2 of 3 letters with a contrast of $1 \%$. CS $=100 \%$ or $\log 2$. Normal score of contrast sensitivity was 2.0 ; that is $100 \%$. Those who had a score below 1.5 were abnormal and this was recorded as decrease in $\mathrm{CS}^{8}$.

SPSS version 22 was used to analyze all the data. For all the variables, frequencies and percentages were calculated and charts were made. For statistical analysis of the data one sample bimonial test was used. Using this test the colour vision and contrast sensitivity among three groups of non diabetics, diabetics without retinopathy and diabetics with retinopathy was analysed keeping CI of $95 \%$ and significance level of 0.05 .

\section{RESULTS}

A total of 242 patients were included in this study. Out of these patients, 161 patients were diabetic and 81 were non diabetic. Out of 161 diabetic patients, 27 (16.8\%) were Type 1 and $134(83.2 \%)$ were Type 2

Table 1: General Characteristics of Patients (242).

\begin{tabular}{llcc}
\hline Variable & & Frequency & Percentage \\
\hline Gender & & \\
& Males & 90 & $37.2 \%$ \\
& Females & 152 & $62.8 \%$ \\
Total & 242 & $100 \%$ \\
Diabetic Status & & \\
& Non Diabetics & 81 & $33.4 \%$ \\
& Diabetics with & 81 & $33.4 \%$
\end{tabular}




\begin{tabular}{|c|c|c|c|}
\hline Variable & & Frequency & Percentage \\
\hline & no & & \\
\hline & Retinopathy & & \\
\hline & Diabetics with & 80 & $33.0 \%$ \\
\hline & Retinopathy & 242 & $100 \%$ \\
\hline \multicolumn{4}{|c|}{ Type of Diabetes } \\
\hline & Type I & 27 & $16.8 \%$ \\
\hline & Type II & 134 & $83.2 \%$ \\
\hline \multicolumn{4}{|c|}{ Control Status } \\
\hline & Good & 33 & $13.6 \%$ \\
\hline & Average & 70 & $28.9 \%$ \\
\hline & Poor & 58 & $24 \%$ \\
\hline
\end{tabular}

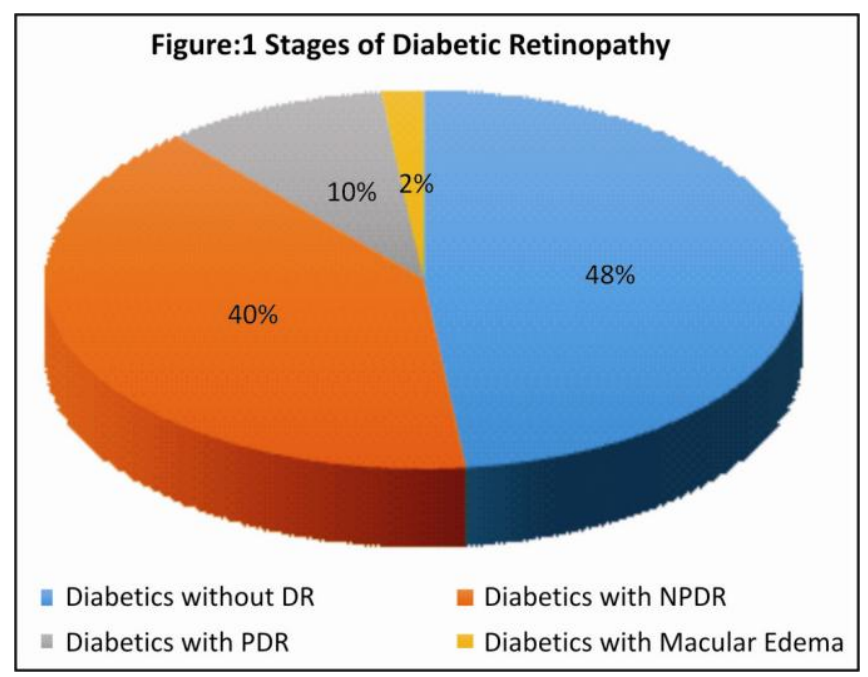

diabetics. One hundred and fifty-two $(62.8 \%)$ patients among this study were female and $90(37.2 \%)$ were male. Patients from 25 to 65 years were included in this study with the age group 61-65 years was featured the most with $16.12 \%$, followed by $46-50$ and $56-60$ years respectively.

This research shows that when diabetic patients, irrespective of type and stage are compared with nondiabetic patients, had a greater percentage of abnormal visual function tests. For details of distance visual acuity, color vision and contrast sensitivity among the three groups, refer to figure 2 , table 2 and table 3 . It was also evident from our results that of all the visual function tests, contrast sensitivity is affected the most in diabetic patients. Comparing all the three visual function tests, CS stands the most important in screening of the diabetic eye disease.

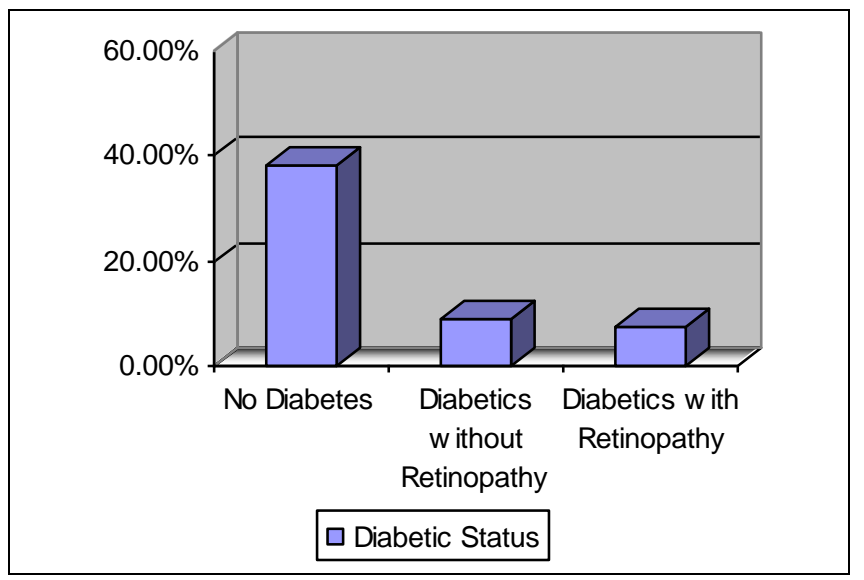

Fig. 2: Relationship between Diabetic Status and the Perfect Eye $(6 / 6$ VA) of the Patients.

Table 2: Relationship between the Diabetic Status and Color Vision of the Patients.

\begin{tabular}{lcccc}
\hline Stage of Diabetes & $\begin{array}{c}\text { CV Right }(>/=\mathbf{1 3}) \\
\mathbf{n}(\boldsymbol{\%})\end{array}$ & $\begin{array}{c}\text { CV Right }(<\mathbf{9}) \\
\text { n (\%) }\end{array}$ & $\begin{array}{c}\text { CV Left }(>/=\mathbf{1 3}) \\
\mathbf{n}(\boldsymbol{\%})\end{array}$ & $\begin{array}{c}\text { CV Left }(<9) \\
\text { n }(\boldsymbol{\%})\end{array}$ \\
\hline No Diabetes & $74(91.3 \%)$ & $7(8.6 \%)$ & $74(91.3 \%)$ & $7(8.6 \%)$ \\
Diabetics without Retinopathy & $72(88.8 \%)$ & $9(11.1 \%)$ & $74(91.3 \%)$ & $7(8.6 \%)$ \\
Diabetics with NPDR & $55(80.8 \%)$ & $13(19.1 \%)$ & $52(85.2 \%)$ & $9(14.7 \%)$ \\
Diabetics with PDR & $9(75 \%)$ & $3(25 \%)$ & $3(18.75 \%)$ & $3(18.75 \%)$ \\
Diabetics with Macular Edema & $0(0 \%)$ & $0(0 \%)$ & $0(0 \%)$ & $3(100 \%)$ \\
\hline
\end{tabular}

Table 3: Relationship between the Diabetic Status and Contrast Sensitivity of the Patients.

\begin{tabular}{|c|c|c|c|c|}
\hline Stage of Diabetes & $\begin{array}{c}\text { CS Right }(>/=1.5) \\
\text { n }(\%)\end{array}$ & $\begin{array}{c}\text { CS Right }(<1.5) \\
\text { n }(\%)\end{array}$ & $\begin{array}{c}\text { CS Left }(>/=1.5) \\
\text { n }(\%)\end{array}$ & $\begin{array}{c}\text { CS Left }(<1.5) \\
n(\%)\end{array}$ \\
\hline No Diabetes & $65(80.2 \%)$ & $16(19.7 \%)$ & $59(72.8 \%)$ & $22(27 \%)$ \\
\hline Diabetics without Retinopathy & $39(48.1 \%)$ & $42(51.8 \%)$ & $32(39.5 \%)$ & $49(60.4 \%)$ \\
\hline Diabetics with NPDR & $25(36.7 \%)$ & $43(63.2 \%)$ & $16(26 \%)$ & $45(73.7 \%)$ \\
\hline Diabetics with PDR & $3(25 \%)$ & $9(75 \%)$ & $3(18.75 \%)$ & $13(81 \%)$ \\
\hline Diabetics with Macular Edema & $0(0 \%)$ & $0(0 \%)$ & $0(0 \%)$ & $3(100 \%)$ \\
\hline
\end{tabular}




\section{DISCUSSION}

The present study revealed an association between impaired visual function tests and the diabetic status of the patients. This study showed that visual acuity markedly decreased with the development of diabetes and that diabetics with increasing stage of diabetic retinopathy are less likely to have $6 / 6$ visual acuity. Reduction in the visual acuity in diabetic patients can be ascribed to increasing stage of DR, hazy cornea and variation in refraction caused by unstable glucose levels in the blood ${ }^{9}$. Various studies have shown that visual acuity can be assessed by different tools and that visual acuity is sufficient to measure the visual impairment in diabetic patients ${ }^{10,11}$.

According to the study published in 2015 there is a marked association between the acquired color vision deficiency and high blood glucose levels ${ }^{12}$. The findings in our study showed that deficiency in color vision is linked to the diabetic status of the patient and as the stage of diabetic retinopathy increases, the likelihood of abnormal color vision also increases. Patients with macular edema are unable to differentiate among short wavelengths of color and thus perform poor on color vision test.

It has been demonstrated in another research that diabetic maculopathy was more likely to cause abnormal color vision ${ }^{13}$. The most authentic justification of this impression is that macula is responsible for central vision and most of the cones are located at macula. Increased blood glucose levels impair macular function to transmit light which affect short wavelength cones giving impaired color vision.

Davies and Ong conducted studies and revealed a significant color vision deficiency in subjects with retinopathy especially in the yellow blue spectral region ${ }^{14,15}$. Similarly Wong et al discovered a positive correlation between color discrimination and extent of retinopathy ${ }^{16}$. Sixty-five percent of the patients who had diabetic retinopathy had abnormal 100 -hue test and those with end stage DR especially macular edema were affected the most. In a separate study, Verrotti et al also found that subjects who had PDR were unable to perform on color vision test ${ }^{17}$.

The present study established that non diabetics have better contrast sensitivity than the diabetic patients, diabetics with no retinopathy performs better on Pelli Robson Chart than the diabetics with NPDR, PDR and macular edema. Starvo and Wood used a high contrast Bailey Lovie chart and Pelli Robson chart in 20 type II diabetic patients and 24 age matched control subjects and established that the loss of CS is more in patients with retinopathy compared to the control subjects ${ }^{2}$.

According to Abrishami et al study, the loss in CS is not only attributed to the retinal changes but also to lens changes ${ }^{18}$. In the present study we have excluded all the subjects with lens changes. A study by Macki and Walsh emphasized on the CS threshold. According to them CS threshold is seen to be increased in diabetic group who had PDR or background DR more than in patients with no retinopathy ${ }^{19}$. This finding is consistent with our results that loss in CS is attributed to the diabetic status and increasing stage of DR of the patients. Lobo et al and Lovestam Adrian et al both showed a relationship of loss of CS with degree of retinopathy ${ }^{20,21}$.

The reason behind decrease in CS in diabetics is not clear. The possible mechanism, which can be accepted theoretically, is the abnormal accumulation of fluid in retina or impairment of neural functions in retina by overloading aldose reductase system. CS is a function of the retina and CS impairment is associated with degree of retinopathy. This makes CS a beneficial tool in finding early retinal changes. The findings of our study are concurrent with previous studies that the leading complication of diabetes is diabetic retinopathy in which all the visual function defects are observed $^{22,23}$.

The limitations of this study included limited time frame to evaluate the diabetes, visual acuity, color vision, contrast sensitivity. Furthermore, it was conducted in a single center and the subjects enrolled in this study were mostly illiterate which makes the results of charts reading less effective.

\section{CONCLUSION}

Visual function tests are easy to perform and can be used to screen the patients with DR in Basic Health Units and Diabetic Clinics. By using these tests diabetic retinopathy can be treated at early stage.

\section{Ethical Approval}

The study was approved by the Institutional review board/Ethical review board.

\section{Conflict of Interest}

Authors declared no conflict of interest 


\section{Authors' Designation and Contribution}

Faryal Ahmed; House Officer: Study design, data collection, manuscript writing, final review.

Faraz Iftikhar Malik; House Officer: Data analysis, manuscript writing.

Chaudhary Ehtsham Azmat; House Officer: Data analysis, manuscript writing.

Ambreen Gul; Senior Registrar: Study Concept, final review.

Ali Raza; Professor: Final review.

\section{REFERENCES}

1. Howes SC, Caelli T, Mitchell P. Contrast sensitivity in diabetics with retinopathy and cataract. Aus J Ophthalmol. 1982; 10 (3): 173-178.

2. Stavrou E. Wood JM. Letter contrast sensitivity changes in early diabetic retinopathy. Clin Exp Optom 2003; 86 (3): 152-6.

3. Olafsdottir E, Stefansson E. Biennial eye screening in patients with diabetes without retinopathy: 10-year experience. Br J Ophthalmol. 2007; 919120: 1599-601.

4. Ali HM, Draman N, Mohamad WM, Embong Z, Ali MH, Yaakub A et al. Predictors of proliferative diabetic retinopathy among patients with type 2 diabetes mellitus in Malaysia as detected by fundus photography. J Taiba Uni Med Sci. 2016; 11 (4): 353358.

5. Stiff AW, Curtis TM, Chen M, Medina RJ, McKay GJ, Jenkins A, et al. The progress in understanding and treatment of diabetic retinopathy. Prog Retin Eye Res. 2016; 51: 156-86.

6. Thayaparan K, Crossland MD, Gary S. Clinical assessment of two new contrast sensitivity charts. Br J Ophthamol. 2007; 91 (6): 749-52.

7. Owidzka M, Wilczynski M, OMulecki WW. Evaluation of contrast sensitivity measurements after retrobulbar optic neuritis in Multiple Sclerosis. Graefes Arch Clin Exp Ophthalmol. 2014; 252 (4): 673-7.

8. Parede T, Torricelli A, Mukai A, Netto M, Bechara S. Quality of vision in refractive and cataract surgery, indirect measurers: review article. Arq. Bras. Oftalmol. 2013; 76: 6 .

9. Cooke JB, Cochrane Al. A practical guide to low vision management of patient with diabetes. Clin Exp Optom. 2001; 84: 155-161.

10. Muneeswar G. Nittala, Laxmi Gella, Rajiv Raman and Tarun Sharma. Measuring retinal sensitivity with the micro-perimeter in patients with diabetes, Retina (Philadelphia, Pa.), 2012; 32 (7): 1302-9.

11. Feitosa-Santana C, Oiwa NN, Paramei GV, Bimler
D, Costa MF, Lago M, et al. colour space distortions in patients with type 2 diabetes mellitus. Visual Neurosci. 2006; 23: 663-8.

12. Radwan TM, Ghoneim EM, Ghobashy WA, Orma AA. Assessment of Colour Vision in Diabetic Patients. Intern J Ophth Res. 2015; 1 (1): 19-23.

13. Shin YJ, Park KH, Hwang JM, Wee WR, Lee JH, Lee IB et al. A Novel Colour Vision Test for detection of Diabetic Macular Edema Colour Vision Test to Detect Macular Edema. Invest OPhthalmol Vis Sci. 2014; 55: 25-32.

14. Davies N, Morland A. Extent of foveal tritanopia in diabetes mellitus. Br J Ophthalmol. 2003; 87 (6): 7426.

15. Ong GL, Ripley LG, Newsom RS, Casswell AG. Assessment of colour vision as a screening test for sight threatening diabetic retinopathy before loss of vision. Br J Ophthalmol. 2003; 87 (6): 747-52.

16. Wong R, Khan J, Adewoyin T, Sivaprasad S, Arden GB, Chong V. The Chroma Test, a digital color contrast sensitivity analyzer, for diabetic maculopathy: a pilot study. BMC Ophthalmol. 2008; 8: 15.

17. Verrotti A, Lobefalo L, Chiarelli F, Mastropasqua L, Ciancaglini M, Morgese G. Colour vision and persistent microalbuminuria in children with type-1 (insulin-dependent) diabetes mellitus: a longitudinal study. Diabetes Res Clin Pract. 1995; 30 (2): 125-30.

18. Abrishami M, Heravian J, Derakhshan A, Mousavi M, Banaee T, Daneshvar R, Moqhaddam HO. Abnormal Cambridge low-contrast grating sensitivity results associated with diabetic retinopathy as a potential screening tool. East Mediterr Health J. 2007; 13 (4): 810-8.

19. Mackie SW, Walsh G. Contrast and glare sensitivity in diabetic patients with and without panretinal photocogulation. Ophthalmic Physiol Opt. 1998; 18 (2): 173-81.

20. Lobo CL, Bernardes RC, Figueira JP, Abreu JR, Cunha-Vaz JG. Three year follow-up study of bloodretinal barrier and retinal thickness alterations in patients with type 2 diabetes mellitus and mild nonproliferative diabetic retinopathy. Arch Ophthalmol. 2004; 122 (2): 211-7.

21. Lövestam-Adrian M, Svendenius N, Agardh E. Contrast sensitivity and visual recovery time in diabetic patients treated with panretinal photocogulation. Acta Ophthalmol Scand. 2000; 78 (6): 672-6.

22. Alió JL, Krueger RR, Bidgoli S. The World Burden of Refractive Blindness. J Refract Surg. 2016; 32 (9): 5824.

23. Wolff BE, BearseJr MA, Schneck ME, Dhamdhere K, Harrison WW, Barez S, et al. Colour vision and neuroretinal function in diabetes. Doc Ophthalmol. 2015; 130 (2): 131-9.

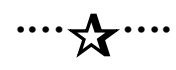

Pakistan Journal of Ophthalmology, 2020, Vol. 36 (1): 62-66 